American Journal of Agricultural and Biological Sciences 4 (3): 230-241, 2009

ISSN 1557-4989

(C) 2009 Science Publications

\title{
Interpretive Perspective of Knowledge Management Stance in Agricultural Knowledge Information System to Fostering Research/Extension Linkage
}

\author{
Iraj Malekmohammadi \\ Department of Agricultural Extension Education, \\ College of Agriculture, University of Tehran, Karaj, Iran
}

\begin{abstract}
Problem statement: Knowledge Management (KM) as a "starter" and Agricultural Knowledge Information System (AKIS) act as an "engine" to sustainable development. Approach: This article explored the role of KM as Agricultural Knowledge Initiative (AKI) to link up agricultural research and extension to foster agricultural development. A dominant-less dominant design was applied to describe the KM and AKIS integration frameworks as an interpretive process. Clarification of KM stance in AKIS was made through hermeneutic approach in the qualitative part of the study. In quantitative part of the study, 'Expedite Finding Transmission of Agricultural Research (EFTAR) Project was explained as the empirical evidence. Results: Although KM and AKIS were not new concepts in agricultural science, but AKI and the New Agriculture (NA), in the way that we intermingled them in this article to encourage the end-users' partnership and agricultural development, are quite new issues. Conclusion: To provide the domain of any use of proposed models elsewhere and facilitate the international application of KM in AKIS and AKI, practical suggestions were presented. Applying this state of art in agricultural development in over 1000 production units, caused obtaining $57 \%$ increase in rain fed wheat production in probationary areas in Iran.
\end{abstract}

Key words: Knowledge management, research/extension linkage, new agriculture, agricultural knowledge initiative, agricultural research extension

\section{INTRODUCTION}

Foskett $^{[16]}$, differentiated knowledge and information, as: 'knowledge is what I know, information is what we know'. Beckman's ${ }^{[8]}$ discriminated data, information and knowledge as follows: Data (text, fact, code, image, sound), information (organized, structured, interpreted, summarized data), knowledge (case, rule, process, model), experience (fast and accurate advice, explanation and justification of results and reasoning) and capability (organizational expertise, core competence). Peter Drucker also defined knowledge as: Information that changes something or somebody either by preparing grounds for action or by making an individual (or an institution) capable of different or more effective action ${ }^{[10,23]}$, is quite exponential, especially, when classified into knowledge categories as tacit; implicit and explicit knowledge $\mathrm{e}^{[25]}$. As a result, in challenging first-order forces explaining entrepreneurship and linking the entrepreneurial process to the dynamic evolution of knowledge, Lhrig $^{[26]}$ conclude that 'knowledge is the enabling force; while individuals, opportunities and environmental forces are second order'. They argue that the origin of opportunities is knowledge that underpins the concept of the individual and the opportunity.

Knowledge tends to fall into three complementary categories. First, tacit knowledge or simply 'knowhow $^{[10,22]}$, which involves perceptions, insights, experiences and craftsmanship While being personal, context-specific, difficult to formalize, difficult to communicate and more difficult to transfer ${ }^{[23]}$, tacit knowledge is from valuable past learning and experiences. It is embedded in individual experience and involves intangible factors. Further, it contains subjective insights, intuitions and hunches. Second, as Davice $^{[11]}$ notes, is "explicit knowledge that is knowledge the knower can make explicit by means of a verbal statement, readily available to the users in many (codified) forms such as books, journals, reports and internet. Moreover, Global Development Network ${ }^{[17]}$ identifies the explicit knowledge as; "what is "captured" in documents, databases, web sites and other knowledge resources versus tacit knowledge that is not primarily "captured", but exists in people's heads and is reflected as insight, judgment, craftsmanship and creativity'. While, explicit knowledge can be readily transmitted to others, Clark ${ }^{[10]}$ indicates that; 'it can be 
easily processed by a computer, transmitted electronically, or stored in databases. And finally, the third category is implicit knowledge which is the result of perception without awareness closer to "knowing that" (explicit knowledge) than "knowing how" (tacit knowledge $)^{[11]}$.

Knowledge management: Historically, the term "knowledge management" was first introduced in a 1986 keynote address to a European Management Conference $^{[6]}$. It is the name of a concept in which an enterprise consciously and comprehensively gathers, organizes, shares and analyzes its knowledge in terms of resources, documents and skills. Hence, it is a set of activities with its own tools and techniques ${ }^{[36]}$ and a method for gathering information and making it available to others ${ }^{[1,2,36]}$. The challenge of $\mathrm{KM}$ is to determine what information within an organization qualifies as valuable. All information is not knowledge and all knowledge is not valuable. The key is to find the worthwhile knowledge within a vast sea of information $^{[24]}$. Liebowitz ${ }^{[25]}$ interprets $\mathrm{KM}$ as:

- The process of providing the ability to organize and locate relevant content and expertise required to address specific business tasks and projects to be able to analyze the relationships between topics, content, people and activity and produce a knowledge map report

- The process of creating values from an organization's intangible assets

- The amalgamation of concepts borrowed from the artificial intelligence/ knowledge based system, software engineering, human resource management and organizational behavior field. Instead of having isolated islands of knowledge, we bridge between these islands

Hawkins $^{[21]}$ defines $\mathrm{KM}$ as the process of transforming information and intellectual assets into enduring values. It connects people with the knowledge that they need to take into action, when they need it.

Although, knowledge management is identified as explicit and systematic management of vital knowledge-and its associated processes of creation, organization, diffusion, use and exploitation ${ }^{[32,38]}$, has attempted to interpret it as "an extension enterprise", to some degree, when it is being considered as: People communicating with each other about what they do, so they can do it better'.

To concluding the above discussion, Fig. 1 illustrates components of $\mathrm{KM}$ to creating tangibleenduring values from an organization's intangible asset.

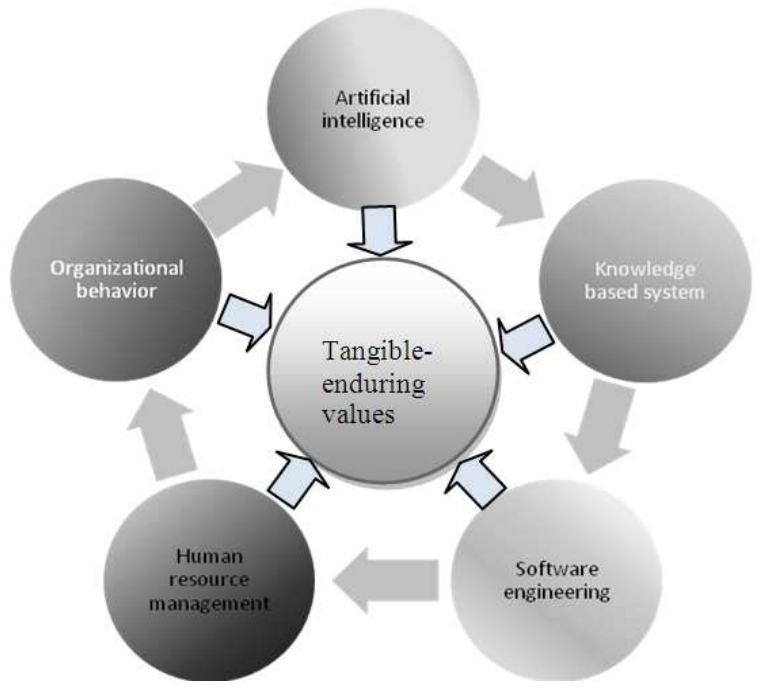

Fig. 1: KM components to creating values from an organization's intangible asset

\begin{tabular}{ll} 
Table 1: Major process of $\mathrm{KM}^{[1]}$ & \\
\hline Process & Stage \\
\hline $\begin{array}{l}\text { Data entry OCR and scanning voice input } \\
\text { Pulling information from various sources }\end{array}$ & Gathering \\
$\begin{array}{l}\text { Searching for information to include } \\
\text { Cataloging, indexing, filtering, linking }\end{array}$ & \\
$\begin{array}{l}\text { Contextualizing, collaborating, compacting } \\
\text { projecting, mining }\end{array}$ & Organizing \\
Flow, sharing, alert, push & Refining \\
\hline
\end{tabular}

As indicated in Table 1, four stages in processing KM are gathering, organizing, refining and disseminating. Each one of these sequential stages is consisted of several activities that must be followed in order ${ }^{[1]}$.

New agriculture: 'The New Agriculture must rely more and more on the capacity of competitive agribusiness to market products that meet animal and plant health standards, as well as food safety, security and environmental regulations. The success of this paradigm depends on technology, information and communication, training and education, promotion of value added products and exchange of experiences among agricultural actors'. Accordingly, no agricultural development project can be fostered other than going through Agricultural Knowledge Management System (AKMS) or what is recently called Agricultural Knowledge Initiative (AKI). The initiative recognizes that research, education and international partnership can all come together to strengthen agricultural sectors. Based on the tradition of US-India collaboration, AKI addresses new challenges and opportunities of modernday agriculture. Through public-private partnerships, it will help to facilitate technology transfer, trade and 
investment and bolster agricultural research, education and extension. In pursuing these objectives, a critical component is cooperation on development of effective policy, regulatory and institutional frameworks ${ }^{[15]}$.

In the combat of new and diverging expectations and challenges facing agriculture and the rural life, a framework to make present agriculture to a fully responsive sector is highly required. Central to this framework is agricultural policy formulation which has received two major features over the last ten to twenty years. First, it is increasingly recognized, in all groups of countries, that agriculture has not only to produce food, although this remains by far its major objective, but also to respond to various other societal needs and second, agricultural policies are more and more determined, or at least influenced, by international decisions ${ }^{[15]}$. The same analysis also indicates that environmentally-sound New Agriculture is needed today to be responsive to the diversity of domestic and international needs. Due to the crucial role of agriculture in our life from one hand and the impact of agricultural illiteracy from the other, this sector almost in all countries is recognized as a strategic sector.

As engine to ensure food safety, food sufficiency and food security $\left(\mathrm{FS}^{3}\right)$, the New Agriculture framework is out to have serious strategies as:

- Revitalize the present agricultural system to become the true engine of economic growth

- Involving large-scale commercial farming; transforming traditional farming into modern commercial farming; increasing productivity of farmers as well as improving farmers' lives and competitiveness; developing agricultural entrepreneurship and entrepreneurship; adopting modern on farm management practices and mechanization; applying appropriate modern technologies; producing high quality and valueadded products; promoting potentials in bio and nanotechnology

- Fostering Genetically Modified Crops (GMC) extension education and thrift-management extension education

- Emphasizing more on agricultural research and development ( $R$ and $\mathrm{D})$ to further improve competitiveness of the sector

- Promote convergence with Information and Communications Technology (ICT)

- Encourage participation of entrepreneurial farmers and skilled workforce

- Streamline the functions of agricultural agencies to enhance service delivery and efficiency
Agricultural Knowledge and Information System (AKIS): According to McDowell ${ }^{[31]}$, Agricultural Knowledge and Information System (AKIS) is a subset of agricultural establishment. It generates and conveys the new knowledge needed to address problems affecting agriculture. Moreover, Zulberti ${ }^{[39]}$ stressed that agricultural knowledge and information system for rural development links people and institutions to promote mutual learning and generate, share and utilize agriculture-related technology, knowledge and information. The system integrates farmers, agricultural educators, researchers and extensionists to harness knowledge and information from various sources for better farming and improved livelihoods'.

KM in agriculture: As Hartwich ${ }^{[20]}$ indicate, to promote new knowledge among farmers, one would need to nurture their extensive tacit knowledge and enable their learning and knowledge flow. As long as agricultural extension (AgEx), potentially, is responsible for need assessment and transferring applicable new knowledge, information and technologies to the end users, it can be translated as a matured knowledge management process in agriculture indeed $^{[29]}$. While actually, KM serves as the "starter", AgEx acts as the "engine" to sustainable agricultural development when we define KM in agriculture as the process of systematically and actively managing and leveraging the stores of knowledge and also the process of transforming information and intellectual assets into enduring values within AKIS partners.

Potentially though, KM is setting stage for AgEx to create more favorable environment for the end users to pursue agricultural development goals and objectives and enjoy a better life. Notably, OSD Comptroller Center ${ }^{[35]}$ illustrates KM as the conjunction of people, technology and process.

More specifically, the overview of KM application in ARE, as Asian Productivity Organization $\mathrm{APO}^{[5]}$ indicated, emphasizes on the three portals of information generators, producers and processors and distributors, namely organizational portal which includes the KM systems, workers portal (researchers and extensionists) and the users or client portal. Each of this portal interact and establish relationships in order to identify, conceptualize and develop, utilize and apply and finally evaluate the information and knowledge for awareness and shared learning. KM approaches must be participatory, dynamic and responsive to the needs of all users. More specifically, it should address the needs and problems of the farmers in order for them to be more productive and competitive. The KM tools must be employed systematically in order to generate information that is relevant, appropriate and timely. 
The Farmers Field School for example starts knowledge identification through technology needs assessment and identifying and inviting experts that can provide their technology needs; they capture and combine knowledge through field research requiring observation of plant behavior, farmers' meetings and consultations and writing reports of their observations and they disseminate knowledge created through exhibits, field days, radio and TV programs. which result in community awareness, re-use of knowledge and learning among farmers (internalization stage). Continuous interaction among the farmers, experts and extension workers result in improving their practices benefiting and practically empowering the stakeholders. This experience proves that KM can operate even outside of the ICT platform.

Successful KM approaches such as FFS must be institutionalized and harmonized with other $\mathrm{KM}$ approaches in every country that utilizes this kind of participatory approach. Lessons learned from the practice of FFS in India, Sri-Lanka, Pakistan, Nepal, Cambodia, Thailand and other Asian countries, which has proven to be very successful in overcoming problems in crop protection of certain crops.

AKIS/KM MIX: One of the purposes of this study is to consider what actually KM is and how can it be applied in AKIS for a better farm management. To achieve this objective it is explained in this article that globally, the internal and external conditions of farming in different countries are changing rapidly. Given the serious conditions facing agricultural systems and farmers per cay, the results of intellectual agriculture that depend on the management power of each farmer and the new agricultural farms that include unconventional new activities have increasingly emerged. For developing such vise farmers, it is indispensable to implement Knowledge Management in order to acquire competitive advantages in agriculture as an effective way to increase the values of the sector as well as the sector actors (producers and consumers) and initiate new agriculture responsive to contemporary agricultural problem which is rapid population and food demand growth from one hand and deficiency of farmers from the other hand.

Agricultural knowledge information system, a transmission system for information and innovative appropriate technology by applying knowledge management in conjunction with AKI strategy is indispensable in the era of new agriculture. However it is proposed in this article that a franchise system, the so called "AKIS actors' partnership" attracts many interested persons' attention as a new type of farming model.
Knowledge, in fact, cannot be easily generated in research organizations and passed down to the extension services and development projects to be diffused among farmers. In response, new ways of managing knowledge have emerged across developing countries by focusing on new dynamics such as participation, collaboration and joint learning between farmers and other agents contributing to the development and diffusion of knowledge beyond the traditional farmer-extension link ${ }^{[20]}$. The point is that, to promote partnership decision making the AKIS/KM MIX should be considered more than simply a collection of its partners, as presently is the case in AKIS and KM when they are acting separately. Rather, applying what Bellinger ${ }^{[9]}$ believes, in order to have a synergic role, "the whole AKIS/KM should represent more than simply the sum of their parts.

Practically, KM/AKIS mix encompasses tripod knowledge (i.e., tacit, implicit and explicit) by helping its partners to diagnose, identify and literalize their strengths, weaknesses, opportunities and threats (SWOT) pertaining to accomplishing their jobs from one hand and to categorize, refine, analyze and replace their inefficient indigenous knowledge by the latest applicable efficient research findings from the other hand, to "connect people to more accurate and up to date sources of information and knowledge" as Ahmed $^{[3]}$ has indicated. This can be manipulated by well educated and trained agricultural graduates and extension agents. But, as Baker and Badamshina ${ }^{[7]}$ stressed as: "The key to a knowledge-based economy is not knowledge-infused products but tacit knowledge that provides the capacity for these knowledge-infused products and for non-codified knowledge services", the problem of today's agricultural graduates is that, basically, they are more knowledge-infused than knowledge-based, therefore, they are not that capable and confident to be able to make on the ground changes as the new agricultural framework demands.

As the result of applying AKI strategies coupled with KM treatment, the following outcomes are expected to be ensured in the new agricultural framework:

- Increase agricultural production by venturing into new sources of growth with greater private sector participation

- Agro-based processing expansion and product diversification

- Strength marketing and global networking

- Enhance incomes for smallholders, farmers and fishermen and

- Improve delivery system service 


\section{MATERIALS AND METHODS}

This interpretive study is conducted by applying a dominant-less dominant (i.e., qualitative-quantitative) design to provide foreground of conceptual frameworks within the context of KM and AKIS to foster agricultural research/extension linkage and demonstrate their applicability for a case situation. Hermeneutic approach is applied to study research/extension linkage in agricultural sector to interpret KM stance in AKIS, to produce an understanding of the context of the KM/AKIS and the process whereby they are influenced by research/extension linkage in agriculture. According to Myers ${ }^{[33]}$, qualitative data sources (may) include observation and participant observation (fieldwork), interviews and questionnaires, documents and texts and the researcher's impressions and reactions. To gather information in the qualitative part, this research typically relied on the analysis of documents and materials as recommended by Marshall ${ }^{[30]}$. Therefore, extensive related research and literature reasoning was reviewed to gather needed data and build up a library of key knowledge assets and processes as indicated by Haggie and Kingstone ${ }^{[18]}$.

Also, an interpretive technique was implemented to analyze data, based on which five structural KM/AKIS models towards AKI and 'new agriculture' atmosphere were developed.

In quantitative part of the study, Expedite Finding Transmission of Agricultural Research (EFTAR) project surveyed by the Office of Extension Planning and Coordination ${ }^{[34]}$ is reported as an empirical evidence that implemented KM in AKIS processes in Iran agricultural development (i.e., boosting wheat production). Notably, in this part, all 186,000 on-farm EFTAR partners (out of 424000 producers) in 310 (out of 1000) production units in farming subsector (out of six Iran agricultural subsectors) were involved in the project during 2004-2006, as indicated in Table 2.

Mean comparison t-test was applied to compare the mean yield of wheat farmers under the EFTAR project and non-EFTAR farmers.

Table 2: Units, projects and client involved in EFTAR Extension Scheme (office of extension planning and coordination, 2006)

\begin{tabular}{|c|c|c|c|}
\hline Ag. sub-sector & Project/producers & Target units & Total client \\
\hline Farming & 600 & 310 & 186000 \\
\hline $\begin{array}{l}\text { Animal husbandry, } \\
\text { poultry }\end{array}$ & 300 & 390 & 87000 \\
\hline Horticulture & 300 & 180 & 54000 \\
\hline $\begin{array}{l}\text { Natural resources } \\
\text { and WATERSHED }\end{array}$ & 600 & 150 & 90000 \\
\hline $\begin{array}{l}\text { Processing and } \\
\text { complementary industry }\end{array}$ & 100 & 40 & 4000 \\
\hline Fisheries and aquaculture & 100 & 30 & 3000 \\
\hline Total & - & 1000 & 424000 \\
\hline
\end{tabular}

\section{RESULTS}

The greatest concern in $\mathrm{KM}$ is to see everything from the eyes of the KM initiator (formal organization) to secure benefits of the organization (employee). While, in the contrary, the greatest concern in AKIS is seeing everything from the eyes of applicants or end users through an informal organization (agricultural community). This is viewed, first and foremost, through AgEx prophecy in terms of unleashing human potentials by creating favorable recognition atmosphere to secure their life fulfillment, basically, when it is integrated with KM. Integration of KM and AgEx led this research to develop the following analytical models.

Rationalizing human resource behavior through synergic KM and Extension integration: Rational decisions need appropriate knowledge and capabilities to managing human behavior. The importance of rational decision making can be adapted from AHIMA Library ${ }^{[2]}$ that 'it's not (only) decisions made by strategists at the top that make or break a company (agricultural sector); but the sum total of the day-to-day decisions made (in reflection to the strategies dealing with agricultural mix) at the front lines of an organization (agricultural community). Better decisions are achieved by spending less (enough) time on information gathering and (much) more on the creative process'.

Although, KM has many similarities with AgEx, but at the same time, it's limited within the boundaries of data, data mining, data processing and pushing the data to the end users which is of course, necessary to manage the formal organization and fulfill its objectives. However, it should not be deemed that the function of encompassing tacit and explicit knowledge is "extension", due to the reality that extension is much further effort than KM in the development process. That is, creating values in AKIS, in conjunction with $\mathrm{KM}$, is rationalizing human behavior when $\mathrm{AgEx}$ converts indigenous knowledge (tacit knowledge) to modern knowledge (codified or explicit knowledge) in agricultural community as shown in Fig. 2.

Regarding what Backman $^{[8]}$ indicated about knowledge as reasoning about information and data to actively enable performance, problem-solving, decision making, learning and teaching, Fig. 2 is comprised of two main decision making engines. First, KM as the main engine to learning and applying knowledge and building up professional characteristic of human resources in the agricultural organization and second, AgEx as the main engine to participative decision making and rationalizing organizational behavior. 


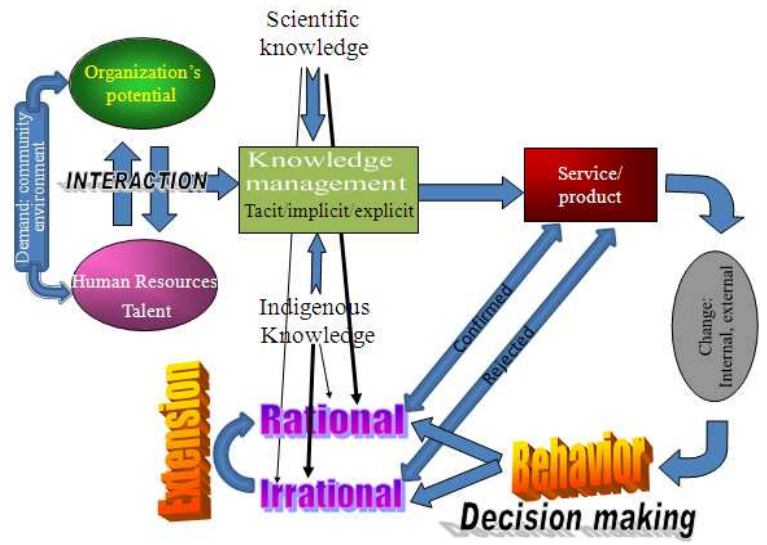

Fig. 2: Rationalizing human resource behavior through synergic role of KM and extension

In reality, combination and interaction of essential factors as human talent and organization's potentials from one side and potential and demands from the community and environment from the other side, provides favorable atmosphere to render needed services or produce demanded commodities. But before that there are numerous decisions to be made and for each to be made plenty of knowledge and information is needed. In making appropriate decision, usually knowledge and information from scientific sources (more rational than irrational) and indigenous sources (more irrational than rational) are needed. Combination of scientific and indigenous knowledge brings about necessary change in actors behavior or performance. While rational behaviors will be acceptable, obviously, irrational behaviors are most likely to be rejected. In this case, $\mathrm{KM}$ in combination with $\mathrm{AgEx}$ is required through the organizational administration to make secure adequate knowledge and information for appropriate decisions. AgEx, in this process, converts irrational behavior to rational behavior by rendering needed (felt or unfelt) right informal education to the right person, at the right place and time and through right technology to the applier and create favorable learning environment to behave rationally, as indicated in the above Fig. 2.

Since, 'all forms of change start with some form of dissatisfaction or frustration generated by data that disconfirm our expectations or hopes and disconfirmation, whatever its source, functions as a primary driving force in the quasi-stationary equilibrium $^{[37]}$, therefore, both AKIS and KM (as similar forms of "change theory") are recognized in this study as desirable and appropriate change process to fulfill the following change theory requirements:
- Description of the change strategy that the program supports

- Definition of the problem to be address

- Quantification of the scope of the needs or assets that make the case selection of the addressee problem

- Acknowledgement of the factors that may influence the ability to create changes in the community

- Application of the best practice research that supports plausible solution strategies for identified problem area

- Statement of the assumptions about why the selected strategies will work in the community in the ways described ${ }^{[4]}$

Amalgamation of KM and AKIS to bring about the rational change: Although, the strategic question of "what is knowledge management all about, especially in agriculture?", is not yet fully responded, but what was concluded so far in this article, shows that as agriculture in the future will be increasingly multifunctional, heterogeneous, complex, knowledge-driven, technologydriven, market-oriented and adapted to available resources, $\mathrm{KM}$ in agriculture also is getting more and more important due to the fact that the key factors driving the New Agriculture will be the application of bio and nanotechnology, information technologies, markets globalization, knowledge and education advancements as well as the consumer preferences. Subsequently, three fundamental and enablers of change as research, education and extension play a synergic and supplementary role whereas, KM plays a complementary role to secure favorable (intentional, rational and positive) change in the system when other components of $\mathrm{KM}$ system play their roles in turn as shown in Fig. 3.

Integrative Research, Extension and Education Engineering (IRE ${ }^{\mathbf{3}}$ ): International, regional and even national global consultations recommend continuous revision, updating, upgrading and advancements in national agricultural research/extension policies, strategies, goals, responsibilities and institutional restructuring plans as are embodied in different country development plans around the world nowadays. These changes should be programmatic and addressed to the need and potentiality of each country ${ }^{[15]}$. Affiliation of KM and AKIS may be conceived as a way of enhancing agricultural sector, yet international expectations also lead us towards involving some complementary fitting enterprises in developing the advanced research/extension linkage model while, it is already realized that a "universal pattern" won't fit all nations. 


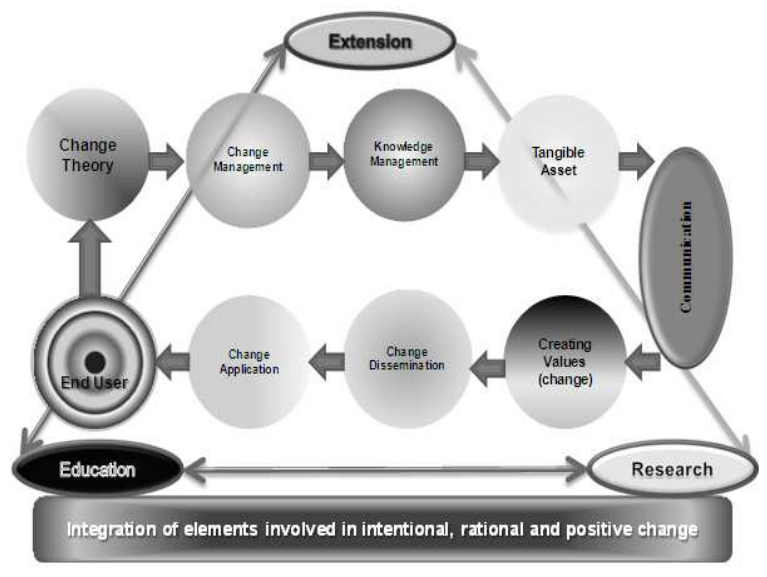

Fig. 3: Integration of research, extension and education with elements involved in intentional, rational and positive change ${ }^{[29]}$

Notably, linking research and extension organizations, is in fact a long historical combat that has never happened in the world, except in the United State under the smith Morill act of $1914^{[27]}$. Although, the linkage has been experienced for 55 years (since 1953) in Iran, as well as many in other developing countries in the world, but in contrast with the US, researchers and extension agents, substantially, were unlinked in doing their job due to the implementation of applied, but not adapted, US pattern.

Pertinent to the discouraging bureaucratic linkage between these sub sectors and having $\operatorname{Harsh}^{[19]}$ stressed that; 'reusability without time cannot be considered because data are continuously being converted into information, information into knowledge and knowledge into wisdom'; as a result knowledge component properties affected. If appropriate knowledge components are selected at a particular moment, then not only it can boost the knowledge faster but, it also will provide more qualitative knowledge.

To pursue this vision, integrative research, extension and education engineering model, as the core strategy of agricultural development, is developed in Fig. 4. The stronger the agricultural KM initiative intermingles agricultural research, extension and education, the stronger the agricultural development to avail in the context of the agricultural community. In fact, AgEx system in synergic conjunction with research and education creates a non-formal, dynamic and generative human capital development learning system, especially, when, according to $\operatorname{ICARDA}^{[22]}$, 'the system [non-formal learning system] consists of numerous complementary and interactive components, each contributing to the success of the total system'.

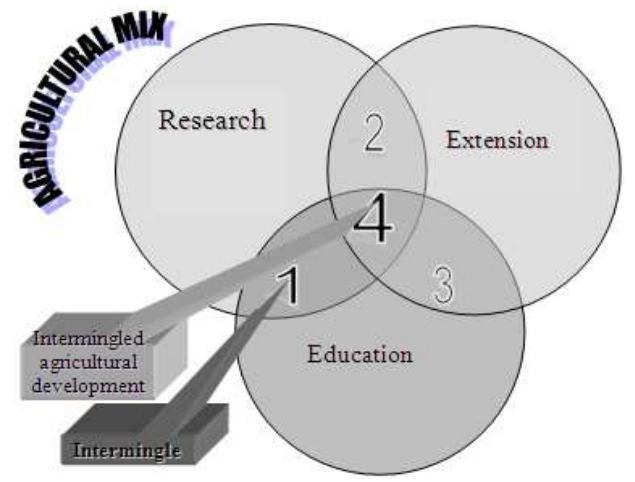

Fig. 4: Integrative research, extension and education engineering $\left(\mathrm{IRE}^{3}\right)$

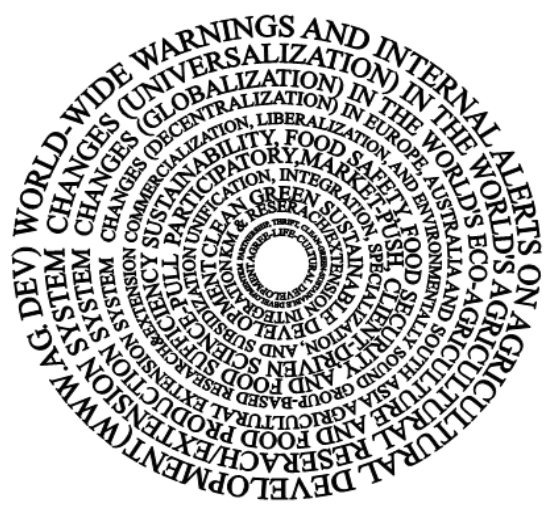

Fig. 5: Global KM-based multi-facet ARE linkage construct

In such a learning system though, 'the individual components are the organization's mission; situation analysis; target audiences; needs assessment; program objectives; content; learning strategies and non-formal learning system, which includes input, evaluation and adjustment. Key supporting components include experience, reinforcement and integration. Development, as indicated in this model, emerges at the core conjunction of three components of intermingled agricultural development as illustrated in Fig. 4.

Agricultural KM/research/extension system architecture: The KM-based, multi-facet agricultural research/extension linkage construct (Fig. 5) was designed in this study as a new seed to agricultural development in Iran applicable in any other developing countries in the world, as the result of considering the above view point in conjunction with Fong and $\mathrm{Su}^{[14]}$ idea when they identified the organization as a knowledge market from a knowledge-based view and suggested that an efficient market mechanism is the key to the retrieval, sharing and further creation of the knowledge base/market. 
Also, coinciding with what Ahmed ${ }^{[3]}$ stated: As we work towards more sustainable development, we must strive not to lose sight of the big picture; we must think and act both globally and localy (globally).

This global model is designed as the result of extensive qualitative study in agricultural status quo, world-wide-global warning and alerts, ongoing issues confronting agricultural development, modernization of extension systems and strategies, research/extension linkage, KM, AKIS and KM stance in AKIS, coupled with years of field experiences in agricultural research and extension, embracing what was recommended by $\mathrm{APO}^{[13]}$ about enhancing extension system in agriculture. It is to provide means to develop on-theground operations in order to pursue AKI and perpetuate self-sufficiency movement better in wheat production in Iran, infrastructure, manipulate and maintain agricultural extension construct by providing it with incremental layers and stages to simultaneously advance agricultural extension in this country. As indicated in Fig. 5, 12 sequential layers, started with world-wide warning and alerts on agricultural development followed by changes in Agricultural Research Extension (ARE) systems; changes (globalization) in the world's eco-agriculture and food production system; changes (decentralization) in the European, Australian and South Asian agricultural extension; commercialization, liberalization and groupbased research and extension; sustainability, food safety, food security, food sufficiency; participatory market-push, client-driven, scientific-pull; unification, integration, specialization and subsidization; cleangreen-sustainable agricultural development; KM based research/extension integration; partnership and thrift, with a paradigm in mind that "failure, or even creeping, is not an option for extension in this eco-agricultural world turmoil.

Application: Research/extension joint projects on producer's farming unit in conjunction with KM/AKIS models presented so far assisted researchers to examine their findings and extension agents to try them out with farmers' participation to solve on-the-farm practical problems in wheat production in Iran. Facilitating and expediting research findings transmission directly from researchers to collaborating farmers monitored by extension, is a national extension scheme in Iran to help the country to achieve self-sufficiency in wheat for few years.

Application of four aforementioned modeled outcomes in Expedite Finding Transmission of Agricultural Research (EFTAR) project in dry farming extension in four provinces in Iran yielded an average of $57 \%$ increase in wheat production in rain fed wheat farming in trial areas by bringing together responsible bodies, under the Ministry of Agriculture and universities. Provincial administrations were encouraged to apply the same package to boost wheat and other major strategic crop production. Consequently, within just few years, Iran has reached to the point to be recognized as a wheat exporting country in 2007, while not long time ago it was among the greatest per capita wheat importers in the world ${ }^{[12]}$. Unfortunately, during three consecutive disastrous (harsh draught) years then after, this project didn't perform well as expected.

The project's vision was to fulfill and secure nation's self sufficiency in major food crops by expanding the range of applied-efficient training to all producers and workers on the farm and processing units to optimize production processes through applying modern and adequate extension approaches and methods (like Farmers Field School FFS) to expedite applicable research findings transmission. Moreover, the mission was to enhance agricultural production towards national self sufficiency through the following strategies:

- Establishing considerable numbers of target production units

- Providing each target production unit with technical-extension multi-dimension guidelines approved by research organization

- Establishing ideal model production units in different local climatic zones to apply recommended procedures and extension guidelines for better quality and quantity productions especially for strategic food items

- Strengthening efficient Research-Extension Application Linkage (REAL)

- Planning participatory umbrella programs to utilize existing human resources, facilities and potentials of all agricultural sub-sectors to perform agricultural extension plans

- Demonstrating successful outcomes of Extension Scheme in National Extensive Pilots all over the country

- Sustaining the slogan: "Making all farms and production units as desirable farmers and unit models" by elevating their feasibility and potentiality

- Developing and extending farming activities through expanding extension education in all production mechanisms including marketing issues in target production units 


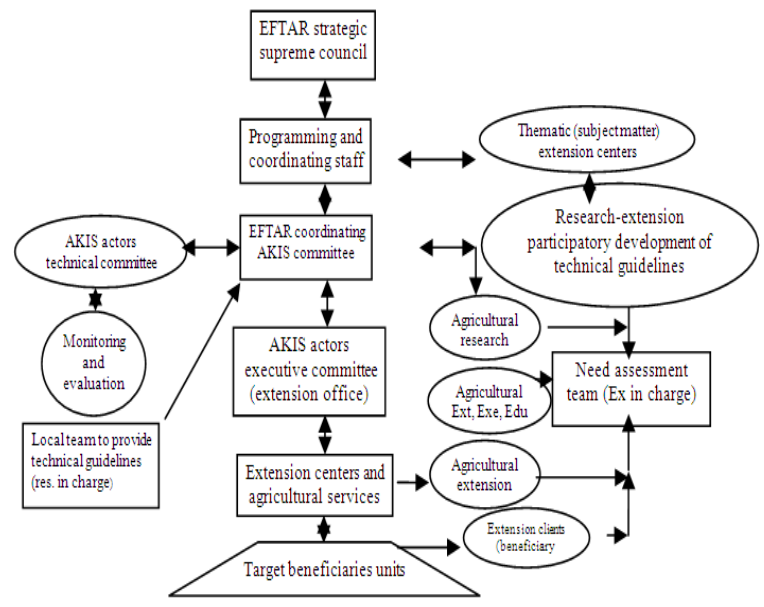

Fig. 6: EFTAR operational chart

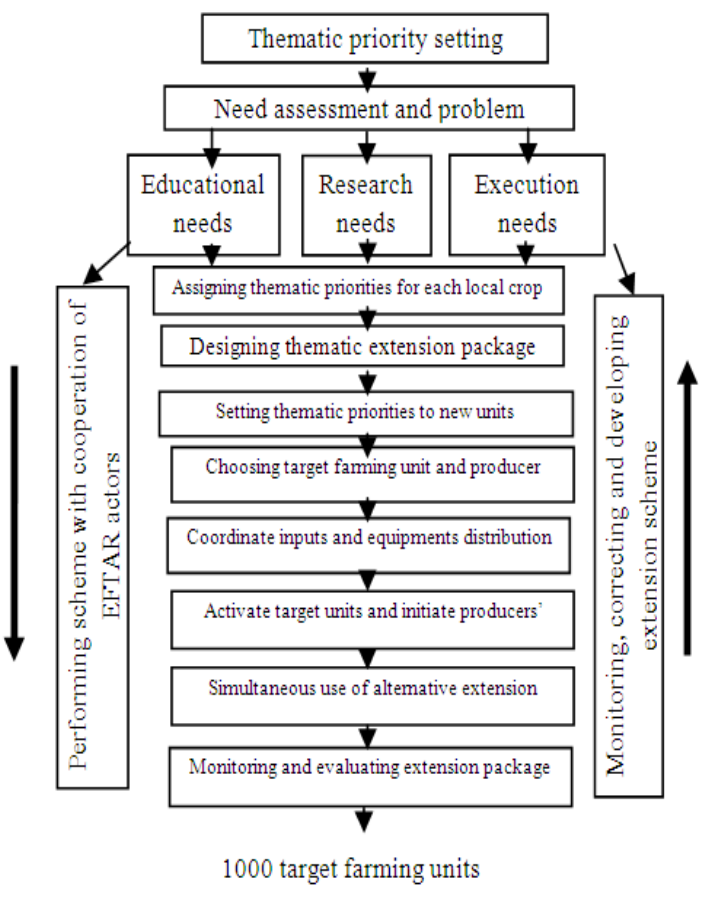

Fig. 7: EFTAR functional chart

Major objectives of EFTAR project were to: Qualitatively and quantitatively increasing agricultural products through expedite transmission of agricultural research findings and technical procedures to producers; enhancing efficiency of production resources and conserving natural resources to produce safe and clean products ${ }^{[34]}$. Figure 6 shows EFTAR organizational chart starting with the strategic supreme council at the top, AKIS at the middle and target beneficiaries units at the bottom line.
As indicated in Fig. 7, there were several major stages in AKIS/KM MIX application to implement research findings on farms as:

- Need assessment and investigating problems in producing regional major crops under supervision of the assisting regional senior extension expert

- Providing local extension packages regarding technical problems by technical team under supervision of the assisting thematic researcher

- Specifying the number of target farming units (Model farming units) in each province by the Extension Programming and Coordinating Office (EPCO)

- Determining the extent and production capacity of farming; horticultural; forestry; pasture; dairy and watershed units

- Providing orientation extension program for farmers to examine their potentiality and choose eligible target client to undertake a minimum-risk cooperation-contract with guaranteed benefits

- Providing inputs and necessary facilities, equipments and encouragements for the chosen target clients to establish and run model farming units

- Initiating technical extension packages to establish and run target farming units under supervision of the assisting researcher

- Performing extension practical packages to train target clients through utilizing different extension method (i.e., exhibition, workshop, field visit, farm day, research finding transmission week)

- Following up target clients continuously by assisting extension expert, researcher, agricultural expert, executives all along the program

- Monitoring, evaluating and adjusting process and procedures by scheme technical committee consisting of all AKIS actors

- Performing all extension activities under the expedite transmission of agricultural research findings (ETARF) extension scheme

- Assisting fresh producers group to transform old farming units to advanced ones by already trained and experienced producers for the next production year

\section{CONCLUSION}

Through over 6000 years of indigenous knowledge management and 800 years of articulated extension as well as 45 years of imposed unlinked agricultural research and extension system and finally 20 years of 
domesticating and internalizing on the ground experiences of thoroughly linking research/extension in Iran, firstly, it was adapted for the first time that this linkage must be based on "partnership" rather than "participatory" involvement, in the first place and secondly, it must be flexible, but not sensitive to change in organizational policies, strategies, administration and personnel, technologies and even farming systems, to farmers' needs. It was also concluded that as we work towards more sustainable agricultural development, we must behave globally (thinking globally and acting locally). At several turning points in research/extension linkage, the linkage should be responsive to new policies and public demands (i.e., strategic research/extension system). The essence of what the linkage is all about is continuous development and appropriate change towards human agricultural resource capital development. To foster this linkage, KM along with AKIS, TQM and ICT should develop New Agriculture, responsive to the national and international demands and expectations.

It is also concluded, for the first time indeed, that research/extension linkage is the act of "agriculture" "[28] for which KM backs up AKIS to care about and share needed knowledge and information with all its actors while motivating their partnership.

As the result of applying this school of thought in agricultural development in over 1000 production units, with more than 424000 producers involved, 57\% increase in wheat production in selected rain fed wheat farming areas was obtained in Iran.

Certainly, the model and on-the-ground experiences attained from KM application in AKIS in wheat production in Iran can fully be adapted and applied in other crops and in other countries.

Remarks: Although, KM and AKIS are not new issues in the world of agriculture, but the way that we intermingled them in this article to encourage the endusers partnership and to foster agricultural development is quite new to the best of our knowledge. Therefore, this innovative implication of AKI was accomplished to link agricultural research and extension, suiting the country towards self sufficiency, initially, in wheat production in Iran. However, it identifies an applicable strategy across other nations.

Since AKIS/KM towards AKI and New Agriculture is a new issue introduced in this article, it is proposed to be adapted in other countries for further investigation as it is being applied, through a proposed research project towards boosting rice production, in Malaysia. Contributing to the development of such a compatible strategy must be one of the pivotal tasks of international agricultural agencies from one side and developing countries from the other. By achieving this, it is hoped that some day a meta-analysis of all AKIS/KM projects to foster research/ extension linkage comes through to find out the best possible ways of boosting agricultural development especially in the era of rapid population and food demand growth to prevent the First Food World War.

\section{REFERENCES}

1. AHIMA Library, 2006. Knowledge Management. American Health Information Management Association (AHIMA). Stillwater, MN., USA.

2. AHIMA Library, 2007. The Web definition of Knowledge Management. American Health Information Management Association (AHIMA). Stillwater, MN., USA.

3. Ahmed, A., 2007. Managing knowledge in the $21 \mathrm{st}$ century and the roadmap to sustainability. GreenLeaf Publication, Sheffield, UK. http://www.allamahmed.org/index.php?option=co m_content\&task=view\&id=405\&Itemid=137

4. Annie, E., 2004. Theory of change: A practical tool for action, results and learning. Organizational Research Services ORS, Seattle, WA., USA. http://www.organizationalresearch.com/publication s/aecf_theory_of_change_manual.pdf

5. Asian Productivity Organization, 2008. Study Meeting on Knowledge Management Tools for Strengthening Agricultural Research and Extension System. Aug. 4-9, APO., Tehran, Islamic Republic of Iran: Tokyo, Japan.

6. Baker, K. and G. Badamshina, 2002. Knowledge management. Knowledge Management Research Library. http://www.about-goal-setting.com/KM-Library

7. Baker, K. and G. Badamshina, 2002. Knowledge Management.

http://www.science.doe.gov/sc5/benchmark/Ch\%2 05\%20Knowledge\%20Management\%2006.10.02.pdf

8. Beckman, T.J., 1999. The Current State of Knowledge Mnagement. In: Knowledge Management Handbook, Liebowitz, J. (Eds). CRC Press, Boca Raton, FL, USA., ISNB: 0849302382, pp: 7-8.

9. Bellinger, G., 2004. Knowledge managementemerging perspective. http://www.welchco.com/02/14/01/60/00/03/0701.HTM

10. Clark, D., 2004 Knowledge. http://www.nwlink.com/ Donclark/knowledge/kno wledge.html 
11. Davice, M., 2001. Knowledge (Explicit and Implicit) Philosophical Aspect. In: International Encyclopedia of the Social and Behavioral Sciences, Smelser, N.J. and P.B. Baltes (Eds.). Elsevier Science Ltd., USA., ISBN: 0080430767, pp: 17500.

12. Deputy Minister for Extension and Farming System, 2006. Organizational chart of the deputy minister for extension and farming system. Ministry of Jihad-e-Agriculture. http://www.tarvij.ir/persia/chart-04asp

13. FAO., 2006. Enhancement of extension system in agriculture. Asian Productivity Organization, FAO, Tokyo, Japan. http://www.apo-tokyo.org/00ebooks/AG-16_EnhanceExtSystem/AG-

16_EnhanceExtSystem.pdf

14. Fang, S. and H. Su, 2008. Organizational knowledge creation: A knowledge market efficiency perspective. Int. J. Knowl. Manage. Stud., 2: 214-235. DOI: 10.1504/IJKMS.2008.018322

15. Foreign Agricultural Service, 2006. Us-India agricultural knowledge initiative fact sheet. United State Department of Agriculture, WD., USA. http://www.fas.usda.gov/ICD/india_knowl_init/facts heet.asp

16. Foskett, C., 1982. The Subject Approach to Information. Linnet Books, Hamden, ISBN: 0208019707, pp: 574.

17. Global Development Network, 2007. Knowledge management as an enabler of change and innovation. Proceeding of the Conference for Policymakers and Practitioners, June 11-13, Cairo, Egypt, pp: 1-10. http://www.gdnet.org/CMS/getFile.php?id=cairo_c onference_program_agenda

18. Haggie, K. and J. Kingston, 2003. Choosing your knowledge management strategy. J. Knowl. Manage. $\quad$ Pract., 5: 33-42. http://jobfunctions.bnet.com/abstract.aspx?docid=316472

19. Harsh, O., 2008. Reusable data, information, knowledge and management techniques. J. Knowl. Manage. Pract., http://www.tlainc.com/articl163.htm

20. Hartwich, F., M. Monge Perez, L. Ampuero Ramos and J.L. Soto, 2007. Knowledge management foragricultural innovation: Lessons from networking efforts in the Bolivian agricultural technology system. Knowl. Manage. Develop. J., 3: 21-37.

21. Hawkins, B., 2000. Libraries, Knowledge management and higher Education in electronic environment. Proceeding of the ALIA Conference, Oct. 24-26 Canberra, Australia, pp: 1-8. http://www.eric.ed.gov/ERICWebPortal/custom/po rtlets/recordDetails/detailmini.jsp?_nfpb=true\&_\& ERICExtSearch_SearchValue_0=ED452865\&ERI CExtSearch_SearchType_0=no\&accno=ED452865
22. ICARDA., 2004. Iran achieved wheat selfsufficiency. International Center for Agricultural Research in the Dry. http://www..icarda.cgiar.org/News/2004News/16D ec04_B.htm

23. Kidwell, J. et al., 2000. Applying corporate knowledge management practice in higher education, Colleges and universities have significant opportunities to apply knowledge management practices to support every part of their mission. Educ. Q., 4: 28-31. http://net.educause.edu/ir/library/pdf/EQM0044.pdf

24. Knowledge Management Research Library, 2009. Knowledge management-can you identify the six main characteristics? http://www.about-goalsetting.com/KM-Library/

25. Liebowitz, J., 1999. Knowledge Management Handbook. CRC Press, FL., USA., ISBN: 0849302382, pp: 328.

26. Lhrig, M., D. Knyphausen-Ausfeb and C. O'Goman, 2006. The knowledge-based approach to entrepreneurship: Linking the entrepreneurial process to the dynamic evolution of knowledge. Int. J. Knowl. Manage. Stud., 1: 38-55. DOI: 10.1504/IJKMS.2006.008844

27. Malekmohammadi, I., 2003. Foundations of Agricultural Extension Education. The History of Agricultural Extension and Education, The University Press, Tehran, Iran, pp: 50-54.

28. Malakmohammadi, I., 2008. Expecting the changer to change, toward clean green sustainable development converting authority-driven-public extension to liberalized-partnership-extension approach. Proceeding of the International Conference on Agricultural Extension, June 16-19, Kuala Lumpur, Malaysia, pp: 1-25. http://www.apeec.upm.edu.my/agrex/FULL\%20P APER\%20PDF\%20(AGREX08)/Iraj\%20malakmo hammadi-keynote\%20speaker.pdf

29. Malekmohammadi, I., 2009. Toward clean green sustainable development to prevent the first food world war, authoritative-public to literalizedpartnership extension approach. Am. J. Agric. Biol. Sci., 4: 49-62. http://www.scipub.org/fulltext/ AJAB/AJAB4149-62.pdf

30. Marshall, C. and G.B. Rossman, 2006. Designing Qualitative Research. Sage Publications, Thousand Oaks, CA. USA.

31. McDowell, G., 2004. The agricultural establishment: giving farmers too much of what they want and not enough of what they need. American Agricultural Economics Association (AAEA). Choices, 19. 
32. Moore, M., 2007. Matt's Knowledge Management Definition. West Wollongong NSW 2500, Cheiftech, Australia.

33. Myers, M.D., 2009. Qualitative Research in Business and Management. Sage Publications, London. UK., ISBN: 10: 141292166X, pp: 296.

34. Office of Extension Planning and Coordinating, 2006. Extension scheme on expedite agricultural research findings. Deputy Minister for Extension and Farming System. Ministry of Agriculture: Tehran, Iran.

35. OSD Comptroller Center, 2002. Knowledge management white paper: Maximizing human potential, benefits of knowledge management. http://eclkc.ohs.acf.hhs.gov/hslc/Professional\%20D evelopment/Organizational\%20Development/Culti vating\%20a\%20Learning\%20Organization/Knowl edgeManagem.htm
36. Rao, M., 2004. Knowledge Management Tools and Techniques: Practitioners and Experts Evaluate KM Solutions. Elsevier, USA., ISBN: 0750678186, pp: 438.

37. Schein, E., 1996. Kurt Lewin's change theory in the field and in the classroom: Notes toward a model of managed learning. J. Syst. Pract. Action Res., 9: 27-47. DOI: 10.1007/BF02173417

38. Skyrme, D., 1999. Knowledge Management Basics to Thrusts, Seven Strategic Levers. David Skyrme Associates Limited, Newbury. England, ISBN: 0750639768, pp: 311.

39. Zulberti, E., 2000. Extension Education Process and Practice. North Carolina Cooperative Extension, North Carolina State University, Raleigh, North Carolina, USA. 